\title{
Permittivity and Electromagnetic Interference Shielding Investigations of Activated Charcoal Loaded Acrylic Coating Compositions
}

\author{
Sharief ud Din Khan, ${ }^{1}$ Manju Arora, ${ }^{2}$ M. A. Wahab, ${ }^{1}$ and Parveen Saini ${ }^{2}$ \\ ${ }^{1}$ Department of Physics, Jamia Millia Islamia, New Delhi 110025, India \\ ${ }^{2}$ CSIR-National Physical Laboratory, Dr. K.S. Krishnan Marg, New Delhi 110012, India \\ Correspondence should be addressed to Parveen Saini; pksaini@nplindia.org
}

Received 6 March 2014; Revised 4 April 2014; Accepted 4 April 2014; Published 4 May 2014

Academic Editor: Yves Grohens

Copyright ( $\odot 2014$ Sharief ud Din Khan et al. This is an open access article distributed under the Creative Commons Attribution License, which permits unrestricted use, distribution, and reproduction in any medium, provided the original work is properly cited.

Acrylic resin (AR) based electromagnetic interference (EMI) shielding composites have been prepared by incorporation of up to $30 \mathrm{wt} \%$ activated charcoal (AC) in AR matrix. These composites have been characterized by XRD, Raman spectroscopy, scanning electron microscopy, dielectric, and EMI shielding measurement techniques. XRD patterns and Raman studies confirm the incorporation of AC particles inside AR matrix and suggest possible interactions between phases. The SEM images show that incorporation of AC particles leads to systematic change in the morphology of composites especially the formation of porous structure. The dielectric measurements show that $30 \mathrm{wt} \%$ AC loading composite display higher relative permittivity value ( 79) compared to pristine AR $(\sim 5)$. Further, the porous structure, electrical conductivity, and permittivity value contribute towards EMI shielding effectiveness value of $-36 \mathrm{~dB}$ (attenuation of $>99.9 \%$ of incident radiation) for these composites, thereby demonstrating their suitability for making efficient EMI shielding coatings.

\section{Introduction}

Electromagnetic (EM) interference (EMI) is an offshoot of explosive growth of electronics and telecommunication in the modern society [1-3]. The EMI among electronic instruments/appliances may lead to degradation of device performance and may even adversely affect human health $[4,5]$. Due to possible hazards of EMI only, the use of EM wave receipting/emitting electronic gadgets is prohibited inside sensitive zones, for example, during flight or inside hospital's ICUs $[1,5,6]$. Therefore, systematic strategies and suitable counter measures are essential to prevent/suppress EMI so as to ensure uninterrupted performance of appliances [1-9]. The primary mechanism of shielding is based on reflection and the material used for shielding by reflection requires mobile charge carriers; that is, shield should have conducting property $[9,10]$. Consequently, metals (in the form of filler, coatings, or laminates) are the most common shielding material which uses primarily reflection mechanism for shielding along with minor absorption component. However, metals suffer from problems like poor wear/scratch resistance, corrosion susceptibility, high density, difficult processing, and high cost $[1,6,9]$. The secondary shielding mechanism is absorption for which shield material should have electrical or magnetic dipoles [9-12] along-with finite electrical conductivity. For such purpose materials with high dielectric constant like $\mathrm{ZnO}, \mathrm{SiO}_{2}, \mathrm{TiO}_{2}, \mathrm{BaTiO}_{3}$, or high magnetic permeability, for example, carbonyl iron, $\mathrm{Ni}$, Co, or Fe metals, $\gamma$ - $\mathrm{Fe}_{2} \mathrm{O}_{3}, \mathrm{Fe}_{3} \mathrm{O}_{4}$, and so forth are used $[1,13]$. However, these materials or their composites possess problems like low permittivity or permeability at gigahertz frequencies, weight penalties, narrow-band action, and processing difficulties $[1,3,13,14]$. Other than reflection and absorption, another mechanism of shielding is multiple reflections, which refer to the reflections at various surfaces or interfaces in the shield [1]. This mechanism requires 
the presence of a large interfacial area and porous structure. An example of a shield with a large surface area is conducting composite material containing filler, foamed composites, and honeycomb structures [3].

Interestingly, the properties of such composites are highly dependent on nature and concentration constituent phases. Carbon based materials (carbon black (CB), graphite, activated carbon (AC), fullerenes, carbon nanofibers (CNFs), cabon nanotubes (CNTs), and recently graphene) are attractive choice as a filler, due to good electrical/thermal conductivity, low density, excellent corrosion resistance, and reinforcing capability $[1,3,7,9,10,12,15-21]$. Particularly, AC with high electrical conductivity and large surface area is an economical alternative. Similarly, acrylics are extremely popular matrix materials due to low cost, solution/thermal processability, high filler reception capacity and ability of acrylic resins (AR) to form hard, abrasion resistant and mechanically strong/tough impermeable coatings [22-24].

Herein we have synthesized porous and electrically conducting AC/AR composites by solvent assisted dispersion of $1-30 \mathrm{wt} \%$ AC particles within AR matrix. The synthesized composites have been characterized by techniques such as XRD, Raman spectroscopy, and scanning electron microscopy. The dielectric and EMI shielding measurements were also performed. These porous compositions, containing electrically conducting filler, are expected to display good EMI shielding performance.

\section{Materials and Method}

Acrylic resin (AR was procured from Pidilite Industries Limited, India), xylene (Rankem, India), and activated charcoal (AC, Merck) were used as received. Formation of AC/AR composites involves the preparation of separate dispersion and dissolution of AC and AR in xylene using magnetic stirrer (REMI 5MLH) followed by their mixing and continued stirring till the formation of viscous syrup. This syrup was poured into a Petri dish and allowed to dry at $50-60^{\circ} \mathrm{C}$ to obtain film/sheet of composite. In a typical synthesis, $14 \mathrm{~g}$ of AR was dissolved in $20 \mathrm{~mL}$ of xylene and a known amount of AC powder was added into it to obtain composites with different $w t \%$, namely, $1,3,5,10,20$, and $30 w t \%$.

\section{Measurement and Characterization}

XRD patterns were recorded using Bruker-D8 advanced diffractometer in the $2 \theta$ range of $10-70^{\circ}$ and using $\mathrm{Cu} \mathrm{K} \alpha$ line as radiation source. The morphological information was recorded using scanning electron microscope (SEM, Leo 440, UK). MicroRaman spectrometer (Lab RAM HR 800, Horiba JY) having $632.8 \mathrm{~nm}$ laser source was used for recording Raman spectra of these samples in $3500-400 \mathrm{~cm}^{-1}$ region. The laser beam was focused on the sample using confocal microscope with LWD $\times 50$ objective. Shielding effectiveness (SE) measurements were performed by placing the samples $(\sim 0.7 \mu \mathrm{m}$ thick) between a $101 \mathrm{GHz}$ frequency microwave source and a horn type antenna-detector system.

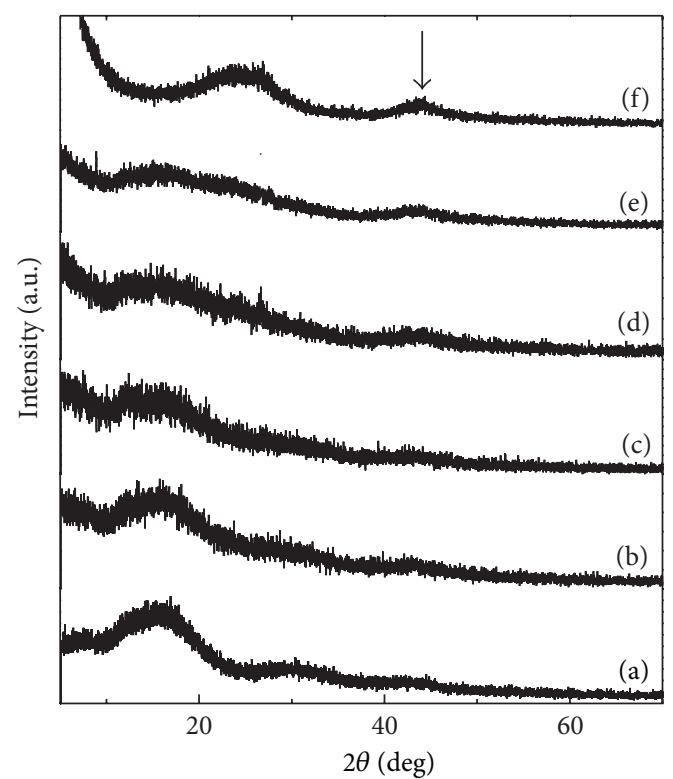

Figure 1: X-ray diffraction patterns of (a) pure AR, (b) $5 \mathrm{wt} \%$, (c) $10 \mathrm{wt} \%$, (d) $20 \mathrm{wt} \%$, (e) $30 \%$, and (f) pure AC.

\section{Results and Discussion}

4.1. Structure Characterization. Figure 1 shows the XRD patterns of pure AR and AC as well as their composites. The characteristic signatures of AR (Figure 1(a)) are located at $2 \theta$ values of $\sim 16^{\circ}$ and $\sim 31^{\circ}$ and $44^{\circ}$, whereas AC's signatures (Figure 1(f)) appear at $25^{\circ}$ and $43^{\circ}$ [24]. The AC/AR composites give superimposed signatures of both phases (Figures 1(b), (c), (d), and (e)) with systematic shifting of the peak positions and relative change in the peak intensity. Particularly, the shifting of $2 \theta=15.95^{\circ}$ peak of AR towards lower angle indicates the interaction between the phases.

4.2. Morphological Details. The SEM image of blank AR film (Figure 2(a)) displays smooth and featureless morphology. However, the incorporation of AC within the AC matrix leads to disturbance of AR's morphology and appearance of roughporous microstructure of AC particles.

As the AC content increases, its signature evolves such that the composite with $30 \mathrm{wt} \%$ loading of AC clearly shows the porous structures and channels (bright regions) made up of electrically conducting AC phase coated and infiltrated with nonconducting AR matrix. As these composites display porous structure and electrically conducting in nature, they are expected to display good EMI shielding efficiency, due to reflection, absorption, and multiple reflection phenomena [1$5,9,12,13,18,25,26]$.

4.3. Raman Spectroscopy. Raman spectra of carbon and its conjugated analogues give two strong bands at 1560 (Gband) and $\sim 1360 \mathrm{~cm}^{-1}$ (D-band) that are dominated by $\mathrm{sp}^{2}$ (graphitic structure) and $\mathrm{sp}^{3}$ (defect structures) hybridized carbons, respectively [27, 28]. Figure 3 shows that, for pure AC, G-band appears at $1582 \mathrm{~cm}^{-1}$ which shifts to $1598 \mathrm{~cm}^{-1}$ 


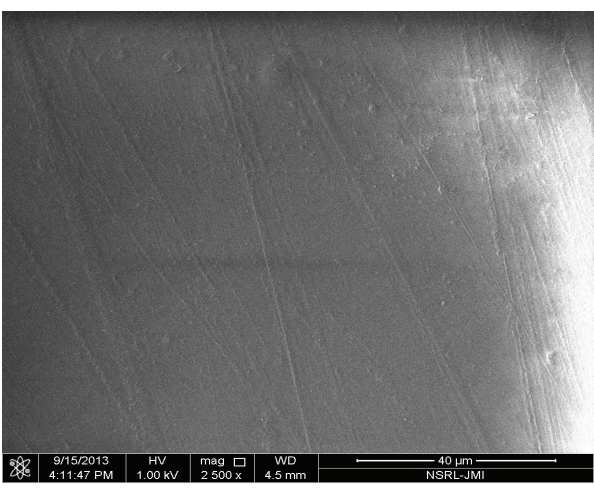

(a)

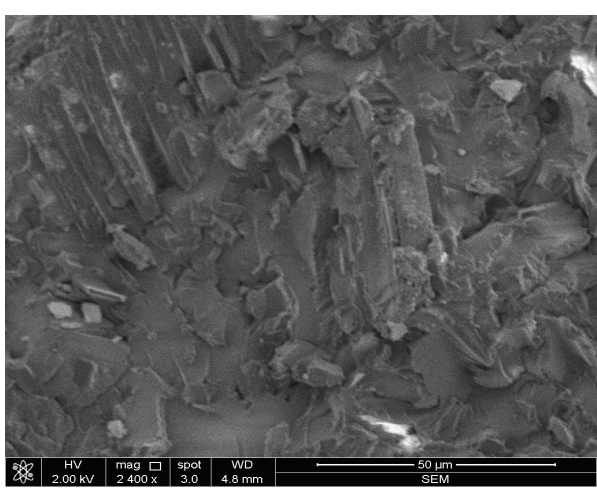

(c)

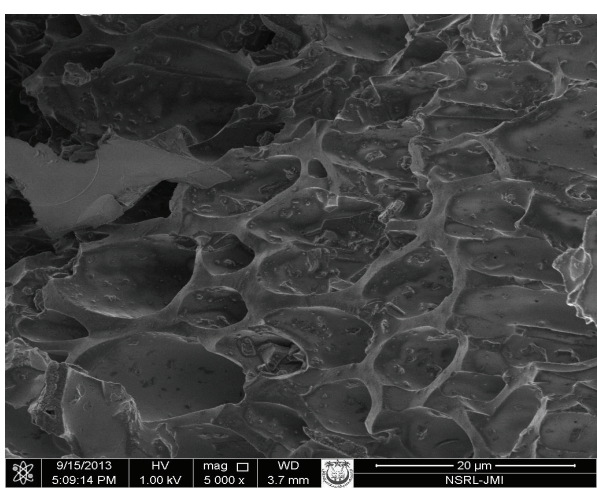

(e)

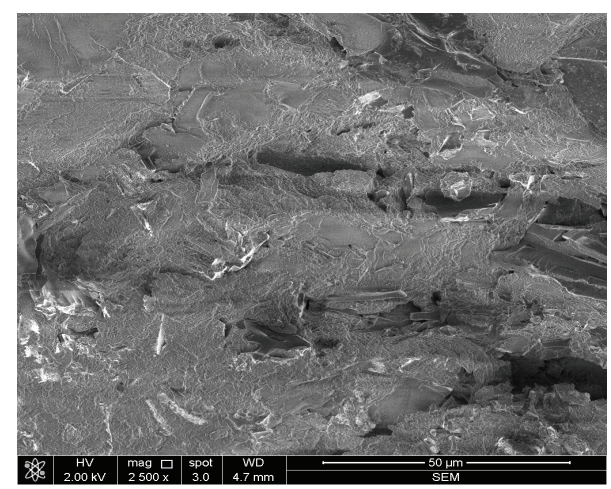

(b)

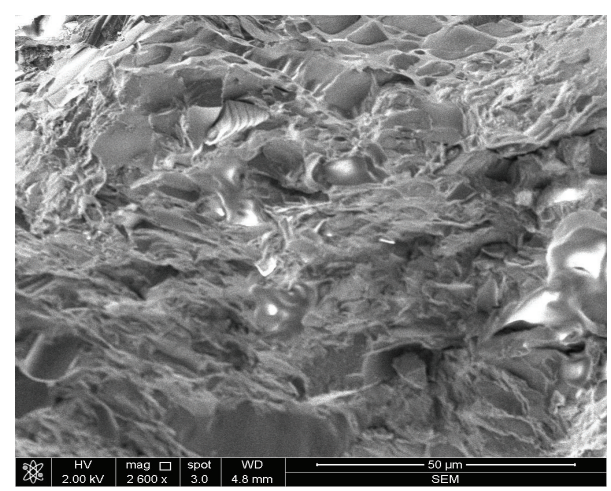

(d)

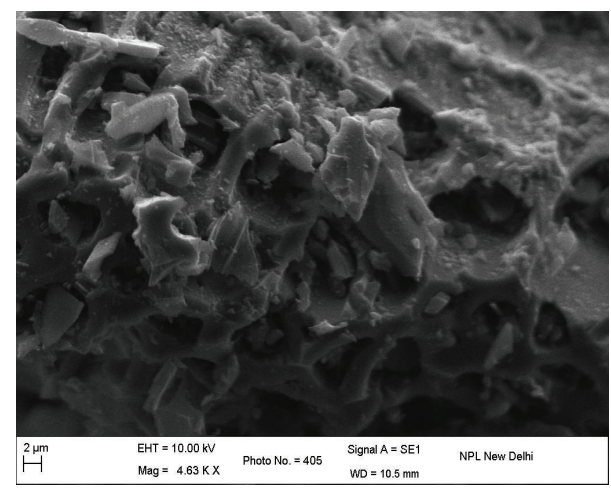

(f)

Figure 2: SEM images of (a) pure acrylic resin, (b) $1 \mathrm{wt} \%$, (c) $5 \mathrm{wt} \%$, (d) $10 \mathrm{wt} \%$, (e) $20 \mathrm{wt} \%$, and (f) $30 \mathrm{wt} \%$ of AC.

on increasing activated carbon percentage in the composites. Similarly, a shift in the disorder band (D-band) from $1304 \mathrm{~cm}^{-1}$ (for AC) to $1320 \mathrm{~cm}^{-1}$ (for $30 \mathrm{wt} \%$ AC containing composite) was observed [27]. Such a shift in the G and D bands on increasing the activated carbon concentration in composites is attributed to the increase in electron-phonon interactions which blueshifts and sharpens the G peak and broadens $\mathrm{D}$ band.

4.4. Dielectric Constant or Permittivity Measurements. The study of dielectric constant as a function of temperature or frequency is one of the most convenient and sensitive methods of investigating the polarization and charge localization effects. It is well known that the polarization of a material is controlled by the electronic, ionic, and dipolar polarization. Electronic polarization occurs during a very short interval of time (of the order of $10^{-15} \mathrm{sec}$ ) and the process of ionic polarization occurs in the range of $10^{-13}-10^{-12} \mathrm{sec}$, while the dipole polarization requires relatively longer time $[1,5,9]$. In case of polar polymers, the dielectric constant begins to drop after a certain critical frequency. The dipole molecules cannot orient themselves in the lower temperature region. However, as the temperature increases, orientation of dipoles is facilitated and this increases the dielectric constant. So in this paper room temperature dielectric constant of $\mathrm{AC} / \mathrm{AR}$ composites has been measured as a function of frequency, as shown in Figure 4, to understand the effect of filler 


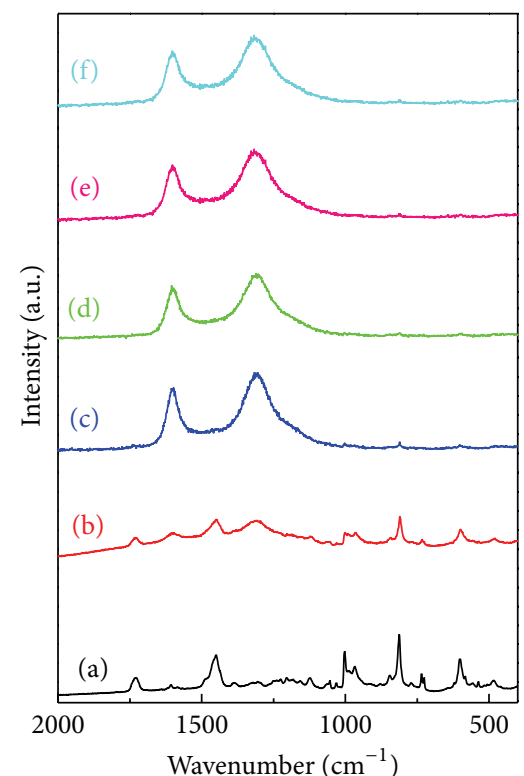

Figure 3: Raman spectra of (a) pure acrylic resin, (b) $1 \mathrm{wt} \%$, (c) $5 \mathrm{wt} \%$, (d) $10 \mathrm{wt} \%$, (e) $20 \mathrm{wt} \%$, and (f) $30 \mathrm{wt} \%$ of AC.

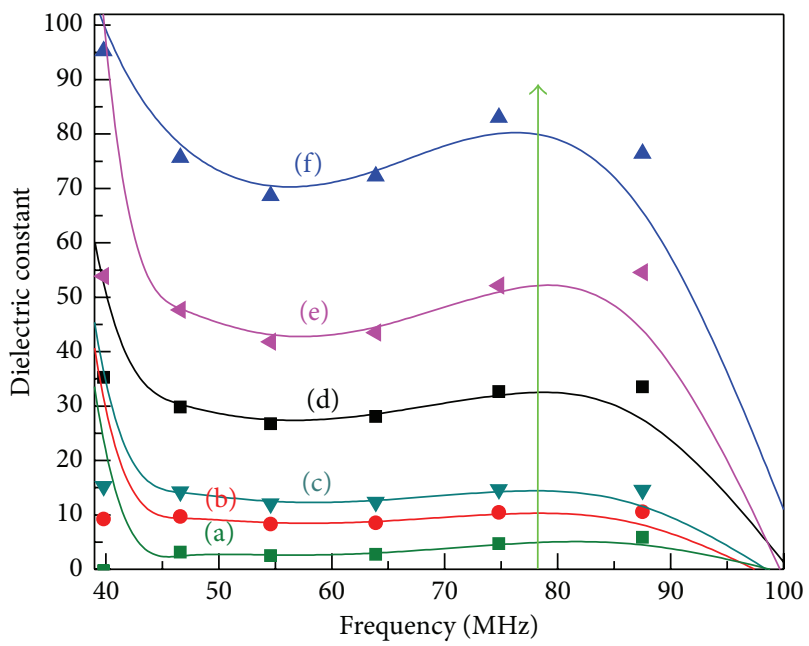

Figure 4: Dielectric measurement of (a) pure acrylic resin, (b) $1 \mathrm{wt} \%$ (c) $5 \mathrm{wt} \%$, (d) $10 \mathrm{wt} \%$, and (e) $30 \mathrm{wt} \%$ of AC.

concentration on polarization behaviour. The results show that, at low frequencies, the electric dipoles have sufficient time to align with the field before the field changes its direction; consequently the dielectric constant is high $[1,29]$. However, at higher frequencies, dipoles fail to follow the rapidly changing electric vector; consequently, the dielectric constant value decreases.

Further, it can be seen (Figure 4) that the increase in AC concentration leads to systematic increase in the relative dielectric constant or permittivity $\left(\varepsilon^{\prime}\right)$, that is, from $\sim 5$ for pure AC to $\sim 79$ for $30 \%$ AC based composites. This can be attributed to the increase in the space charge buildup due to Maxwell-Wagner interfacial polarization $[1,9,18,29]$ occurring as a consequence of large difference in the electrical conductivity of AC (highly conducting) and AR (insulating matrix). It is important to highlight that good dielectric properties and electrical conductivity values are essential requirements for displaying good EMI shielding performance $[1,8,9,30,31]$.

4.5. EMI Shielding Performance. The EMI shielding effectiveness (SE) of a material is the ability to attenuate EM radiation that can be expressed in terms of ratio of incoming (incident) and outgoing (transmitted) power $[1-3,6-9,12,15,18,29-$ 31]. The EMI attenuation offered by a shield may depend on the three mechanisms: reflection of the wave from the front face of shield, absorption of the wave as it passes through the shield's thickness, and multiple reflections of the waves at various interfaces as shown in Figure 5. Therefore, SE of EMI shielding materials is determined by three losses, namely, reflection loss $\left(\mathrm{SE}_{R}\right)$, absorption loss $\left(\mathrm{SE}_{A}\right)$, and multiple reflection losses $\left(\mathrm{SE}_{M}\right)$, and can be expressed as $[1-3,9,18,27]$

$$
\begin{aligned}
\mathrm{SE}_{T}(\mathrm{~dB}) & =\left(\mathrm{SE}_{R}+\mathrm{SE}_{A}+\mathrm{SE}_{M}\right)=10 \log _{10}\left(\frac{P_{T}}{P_{I}}\right) \\
& =20 \log _{10}\left(\frac{E_{T}}{E_{I}}\right)=20 \log _{10}\left(\frac{H_{T}}{H_{I}}\right),
\end{aligned}
$$

where $P_{I}\left(E_{I}\right.$ or $\left.H_{I}\right)$ and $P_{T}\left(E_{T}\right.$ or $\left.H_{T}\right)$ are the power (electric or magnetic field intensity) of incident and transmitted EM waves, respectively. As, the $P_{T}$ is always less than $P_{I}$, therefore, $\mathrm{SE}$ is a negative quantity such that a shift towards more negative value means increase in magnitude of $S E_{T}$. It is important to note that the $S E_{T}$ can be expressed as $[1,6,32,33]$

$$
\mathrm{SE}_{T}(\mathrm{~dB})=-10 \log _{10}\left(\frac{\sigma_{\mathrm{T}}}{16 \omega \varepsilon^{\prime} \mu^{\prime}}\right)-8.68 t\left(\frac{\sigma_{T} \omega \mu^{\prime}}{2}\right)^{(1 / 2)},
$$

where $\varepsilon^{\prime}\left(\mu^{\prime}\right)$ and $\varepsilon^{\prime \prime}\left(\mu^{\prime \prime}\right)$ represent real and imaginary parts of complex permittivity (permeability), respectively, that can be correlated with the total conductivity $\left(\sigma_{T}\right)$ as

$$
\sigma_{T}=\left(\sigma_{\mathrm{ac}}+\sigma_{\mathrm{dc}}\right)=\omega \varepsilon_{o} \varepsilon^{\prime \prime},
$$

where $\sigma_{\mathrm{ac}}$ and $\sigma_{\mathrm{dc}}$ are frequency $(f=\omega / 2 \pi)$ dependent (ac) and independent (dc) components of $\sigma_{T}$. The first and second terms in right-hand side of (2) represent attenuations due to reflection and absorption, respectively. Equations (2) and (3) reveal that, for moderately conducting and nonmagnetic materials $\left(\mu^{\prime} \sim 1\right.$ and $\mu^{\prime \prime} \sim 0$ ), both electrical conductivity and permittivity are important for enhancement of total shielding effectiveness. In the present system, good dielectric and electric properties are expected to improve EMI shielding performance $[1,3,34-36]$.

The EMI shielding plot (Figure 6) revealed that pure AR displays poor EMI shielding response with $\mathrm{SE}_{T}$ value of only $-2.4 \mathrm{~dB}$. However, incorporation of AC phase leads to increase in SE value which scales with AC concentration such that composite containing 30\% AC displays SE value of $-36 \mathrm{~dB}$. It is important to point out that addition of $\mathrm{AC}$ leads to improvement in electrical conductivity as well as 


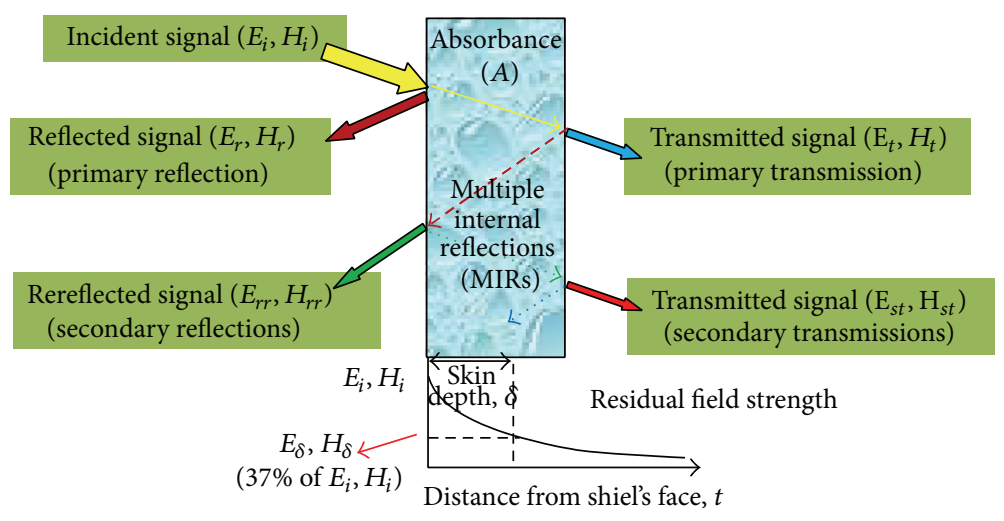

FIGURE 5: Graphical representation of EMI shielding.

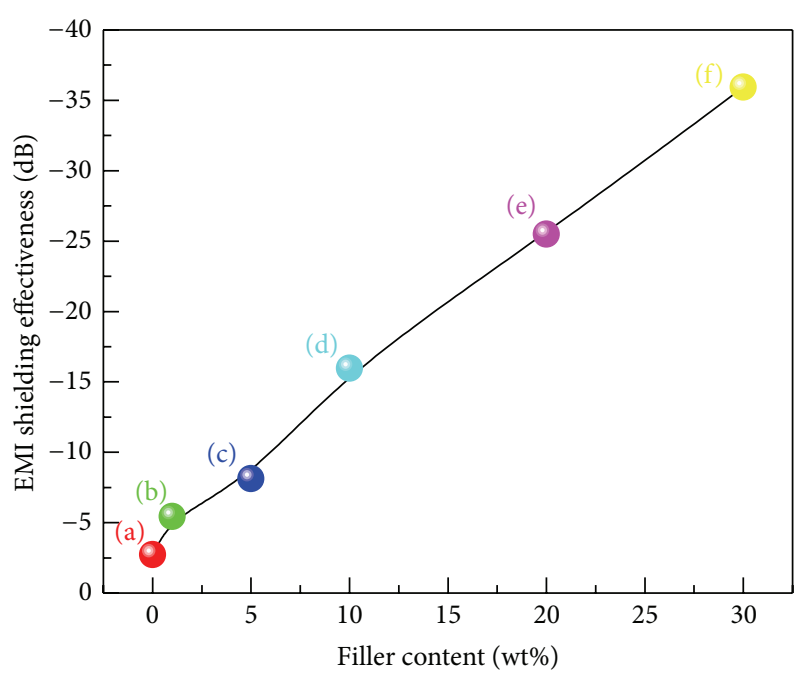

FIGURE 6: EMI shielding effectiveness of (a) pure AR and its composites containing (b) $1 \mathrm{wt} \%$, (c) $5 \mathrm{wt} \%$, (d) $10 \mathrm{wt} \%$, (e) $20 \mathrm{wt} \%$, and (f) $30 \mathrm{wt} \%$ of AC.

permittivity, which collectively contributes towards improved antiradiation performance. The above attenuation value is near the total shielding value of $-30 \mathrm{~dB}$ for phase segregated composites based on $0.66 \mathrm{vol} \%$ [37] loading of reduced graphene oxide in thermoplastic matrix. However, the use of activated charcoal (cheap, porous, and electrically conducting filler), compared to other nanofillers (costly, difficult to process due to agglomeration and dispersion issues, and commercially unviable) to obtain comparable EMI shielding performance (at lesser thickness), highlights the technological importance of our work. It should also be noted that the regions where filler is present are electrically conducting (therefore reflecting), whereas the acrylic containing regions are electrically insulating (therefore nonreflecting). These, two regions form a kind of electromagnetically active pseudopore and also contribute towards multiple reflections. Nevertheless, the high attenuation value in our case (i.e., blocking of $>99.9 \%$ of the incident electromagnetic radiation) demonstrates the technological potential of these composites for making EMI shields.

\section{Conclusion}

AC/AR composites containing up to $30 \mathrm{wt} \%$ AC have been successfully prepared via a facile and scalable solution blending approach. The XRD patterns show superimposed signatures of AC and AR with systematic variation in the peak position and relative intensity. This confirms the incorporation of AC particles inside AR matrix and interactions between phases that were also complemented by Raman spectroscopy results. The morphological investigations revealed that incorporated AC particles regulate the composite's morphology and promote the formation of porous structure. The dielectric measurements revealed that pure AR displays low relative permittivity value $(\sim 5)$ that increases with incorporation of $\mathrm{AC}$ and becomes $\sim 79$ for $30 \mathrm{wt} \% \mathrm{AC}$ containing composite, which also displays EMI shielding effectiveness value of $-36 \mathrm{~dB}$. This shielding value corresponds to blockage of $>99.9 \%$ of the incident electromagnetic radiation and suggests that $\mathrm{AC} / \mathrm{AR}$ composites are promising material for making efficient EMI shields.

\section{Conflict of Interests}

The authors declare that there is no conflict of interests regarding the publication of this paper.

\section{References}

[1] P. Saini and M. Arora, "Microwave absorption and EMI shielding behavior of nanocomposites based on intrinsically conducting polymers, graphene and carbon nanotubes," in New Polymers for Special Applications, A. De Souza Gomes, Ed.A. De Souza Gomes, Ed., InTech, 2012.

[2] H. W. Ott, Electromagnetic Compatibility Engineering, John Wiley \& Sons, Hoboken, NJ, USA, 2009.

[3] P. Saini, "Electrical properties and electromagnetic interference shielding response of electrically conducting thermosetting nanocomposites," in Thermoset Nanocomposites, V. Mittal, Ed., Wiley-VCH Verlag GmbH \& Co. KGaA, Weinheim, Germany, 2013.

[4] L. Olmedo, P. Hourquebie, and F. Jousse, Handbook of Organic Conductive Molecules and Polymers, vol. 2, John Wiley \& Sons, Chichester, UK, 1997. 
[5] P. Saini, M. Arora, G. Gupta, B. K. Gupta, V. N. Singh, and V. Choudhary, "High permittivity polyaniline-barium titanate nanocomposites with excellent electro-magnetic interference shielding response," Nanoscale, vol. 5, pp. 4330-4336, 2013.

[6] P. Saini, V. Choudhary, B. P. Singh, R. B. Mathur, and S. K. Dhawan, "Enhanced microwave absorption behavior of polyaniline-CNT/polystyrene blend in 12.4-18.0 GHz range," Synthetic Metals, vol. 161, no. 15-16, pp. 1522-1526, 2011.

[7] Y. Yang, M. C. Gupta, K. L. Dudley, and R. W. Lawrence, "Conductive carbon nanofiber-polymer foam structures," Advanced Materials, vol. 17, no. 16, pp. 1999-2003, 2005.

[8] N. F. Colaneri and L. W. Shacklette, "EMI shielding measurements of conductive polymer blends," IEEE Transactions on Instrumentation and Measurement, vol. 41, no. 2, pp. 291-297, 1992.

[9] P. Saini, V. Choudhary, B. P. Singh, R. B. Mathur, and S. K. Dhawan, "Polyaniline-MWCNT nanocomposites for microwave absorption and EMI shielding," Materials Chemistry and Physics, vol. 113, no. 2-3, pp. 919-926, 2009.

[10] D. D. L. Chung, "Electromagnetic interference shielding effectiveness of carbon materials," Carbon, vol. 39, no. 2, pp. 279-285, 2001.

[11] S. M. Abbas, A. K. Dixit, R. Chatterjee, and T. C. Goel, "Complex permittivity and microwave absorption properties of $\mathrm{BaTiO}_{3}$ polyaniline composite," Materials Science and Engineering B, vol. 123, no. 2, pp. 167-171, 2005.

[12] D. D. L. Chung, "Materials for electromagnetic interference shielding," Journal of Materials Engineering and Performance, vol. 9, no. 3, pp. 350-354, 2000.

[13] P. Saini, V. Choudhary, N. Vijayan, and R. K. Kotnala, "Improved electromagnetic interference shielding response of poly (aniline)-coated fabrics containing dielectric and magnetic nanoparticles," Journal of Physical Chemistry C, vol. 116, pp. 13403-13412, 2012.

[14] P. Singh, V. K. Babbar, A. Razdan, S. L. Srivastava, and R. K. Puri, "Complex permeability and permittivity, and microwave absorption studies of $\mathrm{Ca}(\mathrm{CoTi})_{x} \mathrm{Fe}_{12-2 x} \mathrm{O}_{19}$ hexaferrite composites in X-band microwave frequencies," Materials Science and Engineering B, vol. 67, no. 3, pp. 132-138, 1999.

[15] N. Li, Y. Huang, F. Du et al., "Electromagnetic Interference (EMI) shielding of single-walled carbon nanotube epoxy composites," Nano Letters, vol. 6, no. 6, pp. 1141-1145, 2006.

[16] P. Saini and V. Choudhary, "Enhanced electromagnetic interference shielding effectiveness of polyaniline functionalized carbon nanotubes filled polystyrene," Journal of Nanoparticle Research, vol. 15, article 1415, 7 pages, 2013.

[17] S. N. Tripathi, P. Saini, D. Gupta, and V. Choudhary, "Electrical and mechanical properties of PMMA/reduced graphene oxide nanocomposites prepared via in situ polymerization," Journal of Material Science, vol. 48, pp. 6223-6232, 2013.

[18] P. Saini, V. Choudhary, K. N. Sood, and S. K. Dhawan, "Electromagnetic interference shielding behavior of polyaniline/graphite composites prepared by in situ emulsion pathway," Journal of Applied Polymer Science, vol. 113, no. 5, pp. 3146-3155, 2009.

[19] J. Wu and D. D. L. Chung, "Increasing the electromagnetic interference shielding effectiveness of carbon fiber polymermatrix composite by using activated carbon fibers," Carbon, vol. 40, no. 3, pp. 445-447, 2002.
[20] E. Varrla, S. Venkataraman, and R. Sundara, "Functionalized graphene-PVDF foam composites for EMI shielding," Macromolecular Materials and Engineering, vol. 296, no. 10, pp. 894898, 2011.

[21] Y. Yang, M. C. Gupta, K. L. Dudley, and R. W. Lawrence, "Novel carbon nanotube-polystyrene foam composites for electromagnetic interference shielding," Nano Letters, vol. 5, no. 11, pp. 2131-2134, 2005.

[22] P. K. Vallittu, "Flexural properties of acrylic resin polymers reinforced with unidirectional and woven glass fibers," The Journal of Prosthetic Dentistry, vol. 81, no. 3, pp. 318-326, 1999.

[23] H.-S. Park, I.-M. Yang, J.-P. Wu et al., "Synthesis of siliconeacrylic resins and their applications to superweatherable coatings," Journal of Applied Polymer Science, vol. 81, no. 7, pp. 16141623, 2001.

[24] S. D. Khan, M. Arora, C. Puri, M. A. Wahab, and P. Saini, "Synthesis and characterization of acrylic resin/activated carbon composites," Indian Journal of Pure and Applied Physics, vol. 52, no. 4, pp. 251-254, 2014.

[25] L. Olmedo, P. Hourquebie, and F. Jousse, "Microwave properties of conductive polymers," Synthetic Metals, vol. 69, no. 1-3, pp. 205-208, 1995.

[26] C. K. Das and A. Mandal, "Microwave absorbing properties of DBSA-doped polyaniline/ $\mathrm{BaTiO}_{3}-\mathrm{Ni}_{0.5} \mathrm{Zn}_{0.5} \mathrm{Fe}_{2} \mathrm{O}_{4}$," Journal of Materials Science Research, vol. 1, no. 1, pp. 45-53, 2012.

[27] P. Saini and V. Choudhary, "Electrostatic charge dissipation and electro-magnetic interference shielding response of polyaniline based conducting fabrics," Indian Journal of Pure and Applied Physics, vol. 51, pp. 112-117, 2013.

[28] R. Kumar, S. R. Dhakate, P. Saini, and R. B. Mathur, "Improved electromagnetic interference shielding effectiveness of light weight carbon foam by ferrocene accumulation," RSC Advances, vol. 3, no. 13, pp. 4145-4151, 2013.

[29] P. Saini and M. Arora, "Formation mechanism, electronic properties and microwave shielding by nano-structured polyanilines prepared by template free route using surfactant dopants," Journal of Materials Chemistry A, vol. 1, no. 31, pp. 8926-8934, 2013.

[30] J. Joo and A. J. Epstein, "Electromagnetic radiation shielding by intrinsically conducting polymers," Applied Physics Letters, vol. 65, no. 18, pp. 2278-2280, 1994.

[31] L. W. Shacklette, N. F. Colaneri, V. G. Kulkarni, and B. Wessling, "EMI Shielding of intrinsically conductive polymers," Journal of Vinyl and Additive Technology, vol. 14, no. 2, pp. 118-122, 1992.

[32] P. Saini, V. Choudhary, and S. K. Dhawan, "Electrical properties and EMI shielding behavior of highly thermally stable polyaniline/colloidal graphite composites," Polymers for Advanced Technologies, vol. 20, no. 4, pp. 355-361, 2009.

[33] P. Saini and V. Choudhary, "Structural details, electrical properties, and electromagnetic interference shielding response of processable copolymers of aniline," Journal of Materials Science, vol. 48, no. 2, pp. 797-804, 2013.

[34] Y. K. Hong, C. Y. Lee, C. K. Jeong, D. E. Lee, K. Kim, and J. Joo, "Method and apparatus to measure electromagnetic interference shielding efficiency and its shielding characteristics in broadband frequency ranges," Review of Scientific Instruments, vol. 74, no. 2, pp. 1098-1102, 2003.

[35] H.-B. Zhang, Q. Yan, W.-G. Zheng, Z. He, and Z.-Z. Yu, “Tough graphene-polymer microcellular foams for electromagnetic interference shielding," ACS Applied Materials and Interfaces, vol. 3, no. 3, pp. 918-924, 2011. 
[36] Y. Yang, M. C. Gupta, K. L. Dudley, and R. W. Lawrence, "A comparative study of EMI shielding properties of carbon nanofiber and multi-walled carbon nanotube filled polymer composites," Journal of Nanoscience and Nanotechnology, vol. 5, no. 6, pp. 927-931, 2005.

[37] D.-X. Yan, H. Pang, L. Xu et al., "Electromagnetic interference shielding of segregated polymer composite with an ultralow loading of in situ thermally reduced graphene oxide," Nanotechnology, vol. 25, no. 14, Article ID 145705, 2014. 

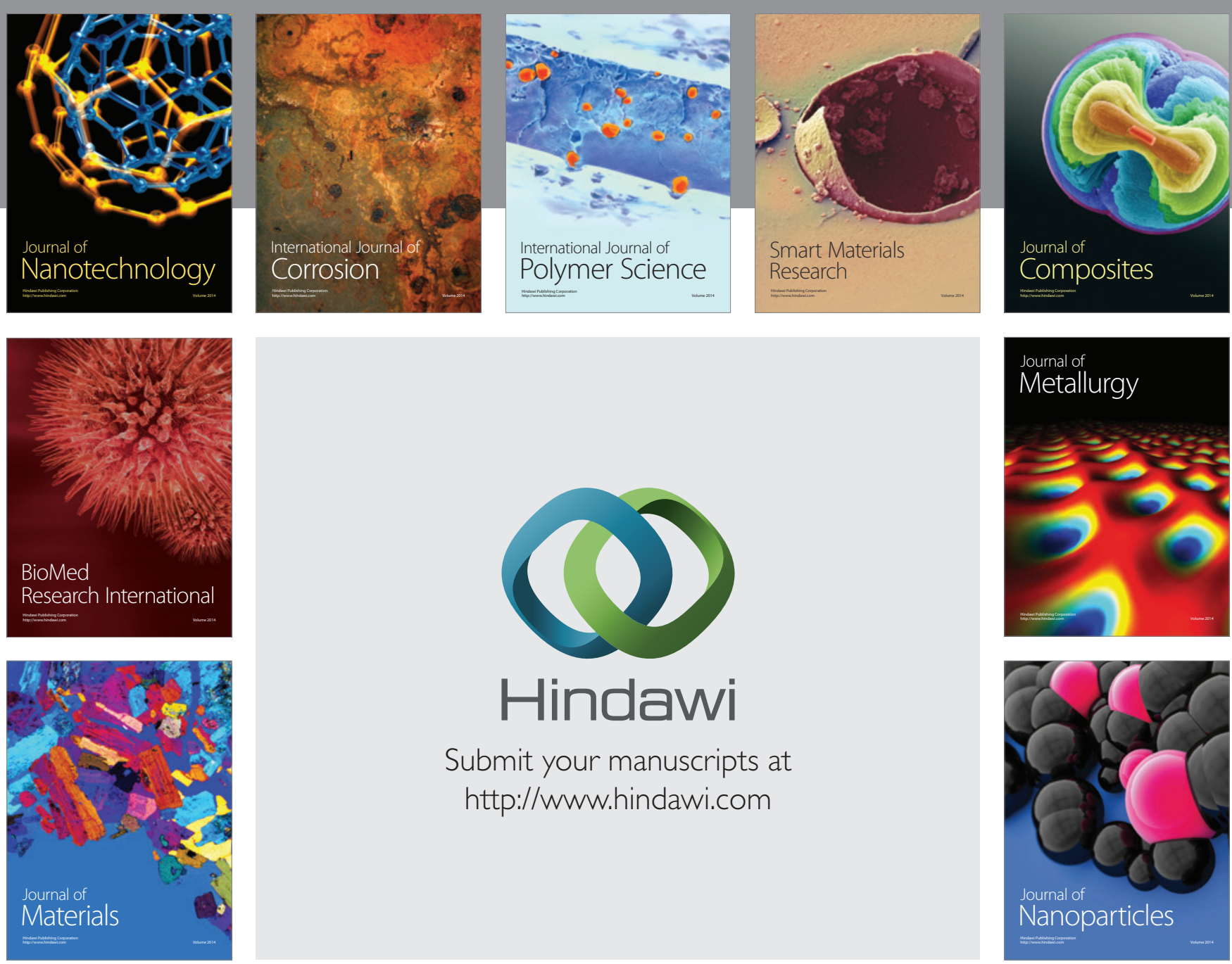

Submit your manuscripts at http://www.hindawi.com
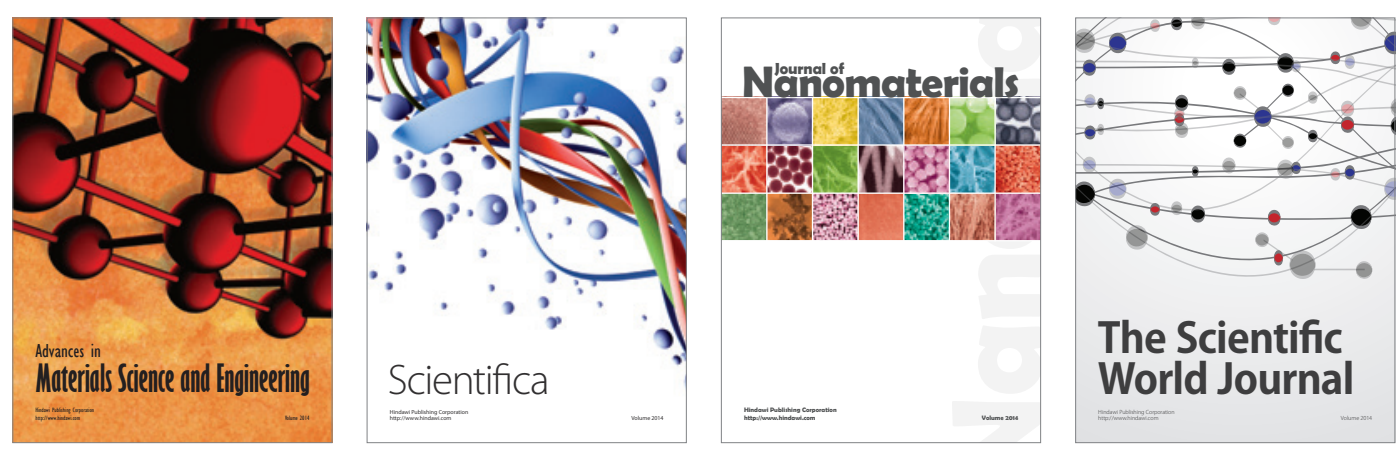

\section{The Scientific World Journal}
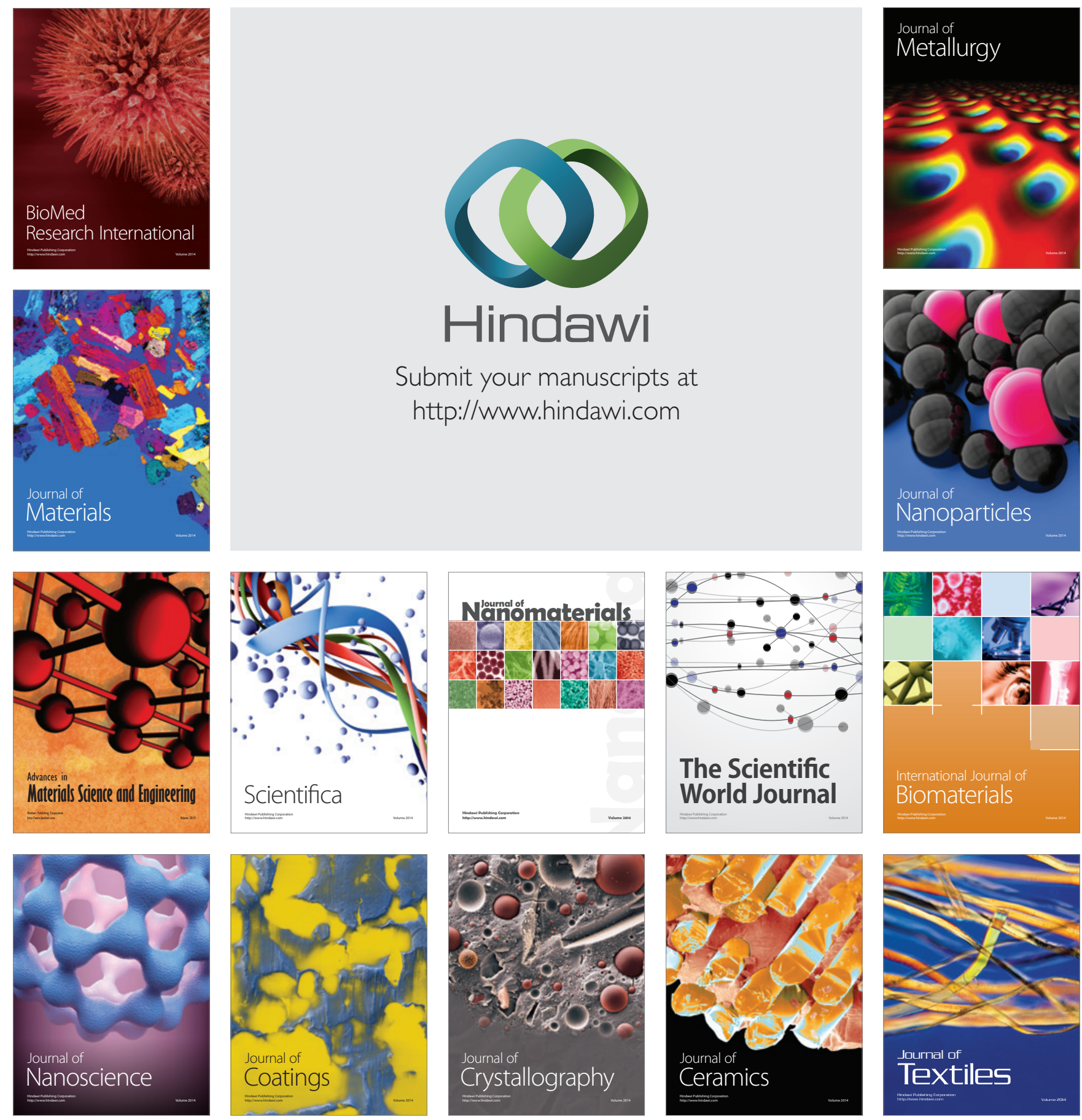